\title{
Erratum to: Adipose tissue lymphocytes: types and roles
}

\author{
S. Caspar-Bauguil • B. Cousin • S. Bour • \\ L. Casteilla $\cdot$ L. Penicaud $\cdot$ C. Carpéné
}

Published online: 29 April 2011

(C) University of Navarra 2011

\section{Erratum to: J Physiol Biochem \\ DOI 10.1007/BF03185938}

The above mentioned review has been published in Journal of Physiology and Biochemistry, volume 65, issue 4, December 2009, pp. 423-436.

One of the authors of this mini review has been listed as 'L. Castiella'. The name of this author should read 'L. Casteilla'.

The online version of the original article can be found at http:// dx.doi.org/10.1007/BF03185938.

S. Caspar-Bauguil $(\bowtie) \cdot$ B. Cousin $\cdot$ S. Bour $•$

L. Casteilla $\cdot$ L. Penicaud

Métabolisme, Plasticité et Mitochondrie, Université de

Toulouse III, UPS, UMR 5241,

Toulouse, France

e-mail: casparbauguil.s@chu-toulouse.fr

S. Caspar-Bauguil • B. Cousin • L. Casteilla $\cdot$ L. Penicaud CNRS UMR 5241,

Toulouse, France

S. Caspar-Bauguil

Service de Biochimie, CHU Rangueil,

Toulouse, France

L. Penicaud

UMR 5548 Université de Bourgogne-CNRS,

Dijon, France

C. Carpéné

Insitut de Médicine Moléculaire de Rangueil, INSERM

U858 and Université Toulouse III, UPS IFR 150,

Toulouse, France 